This is the peer reviewed version of the following article: Rolston, Holmes. Schlick's Responsible Man. Philosophy and Phenomenological Research, vol. 36, no. 2, 1975, pp. 261-267, which has been published in final form at https://doi.org/10.2307/2107060. This article may be used for noncommercial purposes in accordance with Wiley Terms and Conditions for Use of Self-Archived Versions.

Philosophy and Phenomenological Research 36(1975):261-267

\title{
DISCUSSION
}

\section{SCHLICK'S RESPONSIBLE MAN}

In his Problems of Ethics, Moritz Schlick confidently dissolved the free will pseudoproblem, a celebrated dissolution widely considered conclusive, at least until linguistic analyses of "can," "could have done otherwise," etc., reopened the issue. Even in the current debate Schlick remains influential, and his account of responsibility is perennially reprinted as exemplary soft determinism.* But we shall here show that this modern classic is incoherent.

"When is a man responsible?" Schlick answers from the viewpoint first of "objective judgment" and secondly of "subjective feeling.

(A) Responsibility objectively defined. A person is responsible when he offers a "unified point for the application of motive." Knowing who is responsible "is a matter only of knowing who is to be punished or rewarded, in order that punishment and reward function as such-be able to achieve their goal." Let us express Schlick's objective analysis:

(a) Def. obj.: $A$ is responsible in doing $x=$

Threat of punishment will cause $A$ not to do $x$,

or

promise of reward will cause $A$ to do $x$.

"Morally" tacitly prefixes "responsible." Where $x$ is an undesirable act, the penal disjunct ordinarily will operate; where $x$ is desirable, the promissory disjunct operates. But there can be reverse cases. Ineffective threats and promises may be intensified; but if no amount of these will affect $A$ then we do not consider him responsible. Adapting the analysis to past responsibility, we ask whether $A$ might have been so affected. When satisfied about these conditions, we want to say that someone we objectively judge was or is responsible. In this the meaning of responsibility is "completely exhausted."

Responsibility is thus analyzed without residue in causal terms. Schlick assumes that reasons are causes. "We can speak of motives only in a causal context." "The concept of responsibility rests upon

*-'When Is a Man Responsible?' in Moritz Schlick, Problems of Ethics (New York: Prentice-Hall, 1939). pp. 141-158. Perhaps most widely reprinted in Paul Edwards and Arthur Pap, A Modern Introduction to Philosophy, 1st, 2nd and 3rd editions (New York: Free Press, 1957, 1965, 1973). and recently reprinted in Charles L. Reid, Basic Philosophical Analysis (Belmont, California: Dickenson, 1971) and Paula R. and Karsten J. Struhl, Philosophy Now: An Introductory Reader (New York: Random House, 1972). All citations can be readily located in the original or any reprint. 
that of causation." Since a person is a "junction of causes," the issue is simply whether we can further institute a cause that operates "with certainty" to produce conduct. Human conduct is reducible to explanation by causal law; that is the business of ethics. "Every explanation of human behavior must ... assume the validity of causal laws." Determinism is assumed true "at least to the extent required for all purposes of practical life in intercourse with nature and human beings." To insert "probably" or "tend to" in (a) so that $A$ 's action remains open, deliberative, and not in principle predictable vitiates Schlick's whole enterprise.

(B) Responsibility subjectively defined. Schlick next turns to the conditions under which one is prepared to accept responsibility, namely, that one has "acted on one's own desires." What is critical is that we should freely do what we wish, following our "natural desires." Let us express Schlick's subjective analysis:

(b) Def. suj.: $A$ is responsible in doing $x=$ $A$ does $x$, and $A$ naturally desires to do $x$, and

$A$ 's natural desire to do $x$ causes him to do $x$.

The definition may be adjusted for hypothetical use when action is pending.

Compulsion is the opposite of acting in such responsible freedom. Schlick illustrates with a man forced at gunpoint to do what otherwise he would not. The victim would not feel responsible; nor would we hold him so, but rather the gunman. "Compel," an artthropomorphk word, belongs in the context of desiring one thing and being forced to do otherwise. Psychological laws, being natural laws operating through, not against natural desires, do not compel. Civic laws, a paradigm case, compel in very essence. They "often contradict the natural desires of the citizens ... The state does in fact compel its citizens by imposing certain sanctions (punishment) which serve to bring their desires into harmony with the prescribed laws. Schlick sees the subjective analysis as a "welcoming confirmation" of the objective one.

\section{Case I}

But all this is a muddle. Consider the following case:

(1) $A$ naturally desires to do $x$.

(2) Threat of punishment will cause $A$ not to do $x$.

(3) If threat of punishment will cause $A$ not to do $x$, then, if $A$ does $x, A$ is responsible for doing $x$. ( $A$ is responsible should he do $x$.) 
(4) If $A$ does $x, A$ is responsible for doing $x$. ( $A$ is responsible should he do $x$.)

His $x$ ing is an act in which we can hold $A$ responsible, demonstrated by the fact that upon threat of punishment he will not $x$. "Responsible for" is forward-looking; a future locution is parenthesized. Continuing, we add:

(5) If threat of punishment will cause $A$ not to do $x$, then, if $A$ does not $\operatorname{do} x, A$ is responsible for not doing $x$. ( $A$ is responsible should he not do $x$.)

(6) If $A$ does not do $x, A$ is responsible for not doing $x$. ( $A$ is responsible should he not do $x$.)

That is, in his $x$ ing and in his not xing $A$ is amenable to threat of punishment which in the former instance (4) was not applied but hypothesized, and in the latter (5) (as we next suppose) is applied and he answers to it. In the one case we should praise him, in the other blame him; but "responsible," a double-edged word, covers both.

Now consider a further development:

(7) $C$ imposes on $A$ a threat of punishment (as part of civic law) and thereby causes $A$ not to do $x$.

(8) If $A$ naturally desires to do $x$, and if $A$ does not do $x$ under threat of punishment, then $A$ is not responsible for not doing $x$. ( $A$ is not responsible for not having done $x$.)

(9) If $A$ does not do $x, A$ is not responsible for not doing $x$. ( $A$ is not responsible for not having done $x$.)

Under our conditions, (9) can be read categorically: " $A$ is not responsible for not doing $x$." But we retain the hypothetical form to show the contrast with (6). Person $A$ has acted under compulsion contrary to his natural desires. Empathizing, we concur. He was not responsible, he was kept upright by law. "He is hindered from without in the realization of his natural desires," says Schlick of the gunman's victim. But so is the subject of civic law. Schlick conflates many kinds of compulsion (another difficulty with his account), and if, as he says, legal compulsion is a paradigm case, then surely it too relieves moral responsibility. Law for good or revolver for ill, both compel. Subsequently to (7), "responsible for" means "responsible for having done," and is no longer forward-looking. But this does not resolve the conflict. Schlick wants us to attribute responsibility where a person is amenable to punishment. But, he says, we want to accept responsibility only if we act with our natural desires.

Perhaps with a simple revision, we can yet retain Schlick's major 
thesis. Haste at (5) and (6) generates the conflict with (9). On reconsideration we deny (5) and (6). In the context of $A$ 's regularly $x$ ing in accord with his natural desires, it happens that, under $C^{\prime}$ s threat, $A$ does not $x$. On inquiry, the cause of the exception is the novel threat. We then rather say that $C$, perhaps a magistrate, is responsible for $A$ 's not xing. Asymmetrically, if $A x^{\prime} \mathrm{s}, A$ is responsible; if $A$ does not $x, C$ is. Witness the gunman and his victim. Hence, resolving the conflict with (9):

(5') If $C^{\text {'s }}$ threat of punishment will cause $A$ not to do $x$, then, if $A$ does not do $x, C$ is responsible for $A$ 's not doing $x$.

(6') If $A$ does not do $x, C$ is responsible for $A$ 's not doing $x$.

(6") If $A$ does not do $x, A$ is not responsible for not doing $x$.

This account would be consistent with Schlick's realization that responsibility shifts from the compelled to the compeller.

But by just this shift we would doubly undermine Schlick's causal reduction of responsibility. First, responsible action in absence of sanctions is thereby once-removed from causal laws. Since, objectively, we observe responsibility only to destroy it, responsibility is always hypothetical一supposed for another occasion than the one under observation. It cannot be directly verified, since no act done under sanction is done responsibly; it can at best be indirectly verified, that is, supposed for earlier acts by seeing that on a subsequent occasion, similar in all relevant respects except that a sanction is levied, the agent acts differently. Curiously, it is inferred only from a condition of nonresponsibility. So, like nonperceived objects, responsibility only exists when not observed. Like a cross-wired refrigerator light, only on when the door is shut, responsibility is only "on" when not objectively observed. Oddly, the necessary and sufficient condition of $A$ 's responsibility in his $x$ ing without sanctions is whether he might have been with sanctions made not responsible. Surely it is a very doubtful criterion of responsibility, even when acting in accord with one's natural desires, that one is subject to the operation of a sanctioning causal law which will operate "with certainty" to alter his conduct and destroy his responsibility. (We argue below, in Case II, that on some occasions it is rather the man who cannot be caused to act otherwise that we judge most responsible.)

Secondly, and worse, since there is no responsible action in the presence of sanctions, the revision here destroys Schlick's principal claim: that responsibility is grounded in a causal relationship. Ethics, Schlick is contending, is the science of morally responsible behavior given causal explanation, enabling us to predict and alter the 
actions of responsible men. "It is certain," he concludes, "that we can apply the concept of responsibility to human conduct insofar as the causal principle holds." Both objective and subjective analyses show "causality as the presupposition of responsibility," and reconcile the two. But, objectively, Schlick cannot bring moral responsibility under the reach of sanctioning causal law, unless he intends for us to accept as morally responsible actions not only those which an agent does in absence of sanctions but also those he does under sanctions. Hence (5) and (6) must be implications of Schlick's objective account (though contradicted by the subjective account), else, alas, responsibility is exempt from precisely the causal law he proposes. If, in revision, Schlick were to accept (5'), $\left(6^{\prime}\right)$, and (6") to achieve consistency with his subjective account, the price would be a concession that responsibility is not compatible with the operation of sanctioning causal law, since it vanishes when law is exercised. So soon as this law operates, it renders the previously and hypothetically responsible agent not responsible. So far from being amenable to such causal law, responsibility has quite eluded it. Let this law touch it, and it collapses. It exists only in its absence, never in its presence. Persons may be supposed responsible, but no one can be held responsible, except by destroying his responsibility and converting it to nonresponsibility. Of course, $A$ responds, he is responsive, and, by straining the language, response-able, or responsible. But his responsibility is morally denatured; What is left is a shell. The moral freight shifts to $C$, the compeller. Civic laws work only on the responsible, the "compel-able," but in their compelling work they destroy responsibility. Thus such revision of Schlick fails, since no moral responsibility in $A$ has been included within the scope of sanctioning causal law.

In an alternate revision, we might retain Schlick's basic conditions, yet broaden the context of "natural desires" to make $A$ 's conduct consistent with both analyses. $A$ naturally desires to $x$ with impunity; when that becomes impossible, then $A$ does not $x$. The objective threat works; subjectively, he does what, mindful of sanctions, he naturally desires. So there is no conflict. If $A$ is a thief, this first seems plausible. But witness again the gunman's victim who does what, situationally, he naturally desires to do. If consistent, we ought to attribute moral responsibility to the victim. But we attribute only an uninteresting, denatured responsibility. The moral burden shifts to the gunman. Worse than that, if "natural desires" includes what one desires mindful of sanctions, then there can be no compulsion, 
for one cannot act in context against his natural desires. The alternate revision proves trivial.

When, as compellers, we show a man answerable to punishment, we do not, as Schlick would have it, show his (moral) responsibility. Quite the contrary, we render him nonresponsible and become responsible in his stead.

\section{Case II}

Contrast this now with a second case.

(1) $B$ naturally desires to do $x$.

(2) Threat of punishment will not cause $B$ not to do $x$.

(3) If threat of punishment will not cause $B$ not to do $x$, then, if $B$ does $x, B$ is not responsible for doing $x$. ( $B$ is not responsible should he do $x$.)

(4) If $B$ does $x, B$ is not responsible for doing $x$. ( $B$ is not responsible should he do $x$.)

Schlick's example, a plausible one, is that of an insane person who commits a wrong. We do not consider him responsible, since "he offers no unified point for the application of motive." But let us choose another example. Let $x$ be civil disobedience contemplated by $B$, one of those intractable persons who cannot be intimidated by the city fathers. By Schlick's objective analysis, $B$ likewise is not responsible. There is an autonomous natural desire to be civilly disobedient, in obedience (let us say) to his conscience; and no amount of threat of punishment $\cdot$ will cause him to act differently. To complete the case:

(5) $C$ imposes on $B$ a threat of punishment (as part of civic law), but despite the threat designed to compel him not to do $x, B$ nevertheless does $x$.

(6) If $B$ does $x, B$ is responsible for doing $x$ (for having done $x$ ), since he acts in accord with his natural desires,

We must now reverse ourselves. By Schlick's subjective analysis, $B$ is responsible. $B$ would doubtless concur.

Have we overlooked the promissory disjunct of definition (a)? Reward the protester with relevant social action and, unless he is indeed insane, he will desist. But this solution has only prima facie plausibility. Other rewards, bribes, will not work. The only functional "reward" is a capitulation to what $B$ desires which essentially dissolves the case. The "reward" does not function as such. Complying with the object of his natural desires is no longer a case of applying motives to $B$ so as to alter the conduct that would otherwise issue from his natural desires. This is a very odd "reward" that leaves us asking who has altered the conduct of whom. One can analogously 
reward a car thief so as to prevent his theft by giving him the car.

Schlick hopes to make the case that the responsible man is the man both on whom and in whom causation operates effectively, and to leave causation unimpaired in both cases. But, to return to person $A$, it is just this kind of man, who can be caused to act, that we do not consider responsible in the moral sense. It is open to question whether he has acted at all. We can manipulate him, as we can dogs and machines. They all respond, but not morally. Schlick's incoherence is to conclude that this compellability is moral responsibility, with the simultaneous admission that when causality works compellingly on us it does so with violence to the causality that works freely in us.

Indeed, we often consider $B$ most responsible precisely when he cannot objectively be caused to act. Granting his sanity, we count this moral responsibility, one which, in favorable cases, we. admire the more because the agent cannot be manipulated. His desires originate within him, and he courageously and freely acts despite intimidation. Since we cannot influence him, he is the author of his deeds; we are not. (Doubtless sometimes too, we would allow $B$ responsibly to desist under extreme threat: in any event our judgment of responsibility is complex, and cannot be reduced to any tight causal relation between sanctions and acts.) It is sufficient to undermine Schlick's account that on at Ieast some occasions $B$ 's resolute persistence in xing will confirm his responsibility, while his ready desisting will lessen it. Whether such responsible authorship of one's own deeds involves a contracausal freedom is a very much larger issue than can be resolved here. Certainly the solution, or dissolution, is not nearly so simple as Schlick has proposed. Meanwhile, his hope of retaining responsibility under ethics as an applied science has collapsed.

HOLMES ROLSTON, III.

COLORADO STATE UNIVERSITY. 